\title{
NEW NONINVASIVE TEST ALTERNATIVE TO ALLEN'S TEST: SNUFF-BOX TECHNIQUE
}

Kazuhiro Kochi, MD, Taijiro Sueda, MD, Kazumasa Orihashi, MD, and Yuichiro Matsuura, MD, Hiroshima, Japan

Radial artery (RA) harvesting for coronary artery bypass may lead to ischemia of the digits if the collateral hand circulation is inadequate. ${ }^{1}$ Although Allen's test is a subjective method with a high possibility of false negative and positive results, it is the most commonly used screening method to evaluate the adequacy of collateral hand circulation before RA harvesting for coronary artery bypass grafting. ${ }^{2,3}$ To

From the First Department of Surgery, Hiroshima University School of Medicine, Hiroshima, Japan.

Received for publication April 26, 1999; accepted for publication June 3, 1999.

Address for reprints: Kazuhiro Kochi, MD, First Department of Surgery, Hiroshima University School of Medicine, 1-1-1 Kasumi, Minami-ku, Hiroshima,734-8551, Japan.

J Thorac Cardiovasc Surg 1999;118:756-8

Copyright (C) 1999 by Mosby, Inc.

$0022-5223 / 99 \$ 8.00+0 \quad \mathbf{1 2 / 5 4 / 1 0 0 6 1 5}$ develop more objective methods than Allen's test, we studied hand circulation with RA compression using a 7.5 MHz color Doppler study and monitoring of pressure in the digits.

Methods and results. The subjects were 10 healthy surgical residents in whom Allen's test yielded negative results (9 men and 1 woman, aged 25 to 39 years). The Doppler signals of the RA in the anatomic snuff-box were measured with RA compression in the color Doppler mode of a $7.5 \mathrm{MHz}$ echocardiographic system (PLF-703NT, Sonolayer SSA260A, Toshiba, Tokyo, Japan). The probe was placed next to the snuff-box. The insonation angle was corrected to less than $15^{\circ}$ to visualize the optimal Doppler flow. Digital artery systolic pressure with RA compression was measured with a commercially available blood pressure monitor (HEM-808 F, Omron Co, Tokyo, Japan). The Wilcoxon signed-rank test was used for the statistical analysis. Color Doppler study revealed that the direction of the flow was backward in all hands with RA compression. Thus the Doppler signals away 


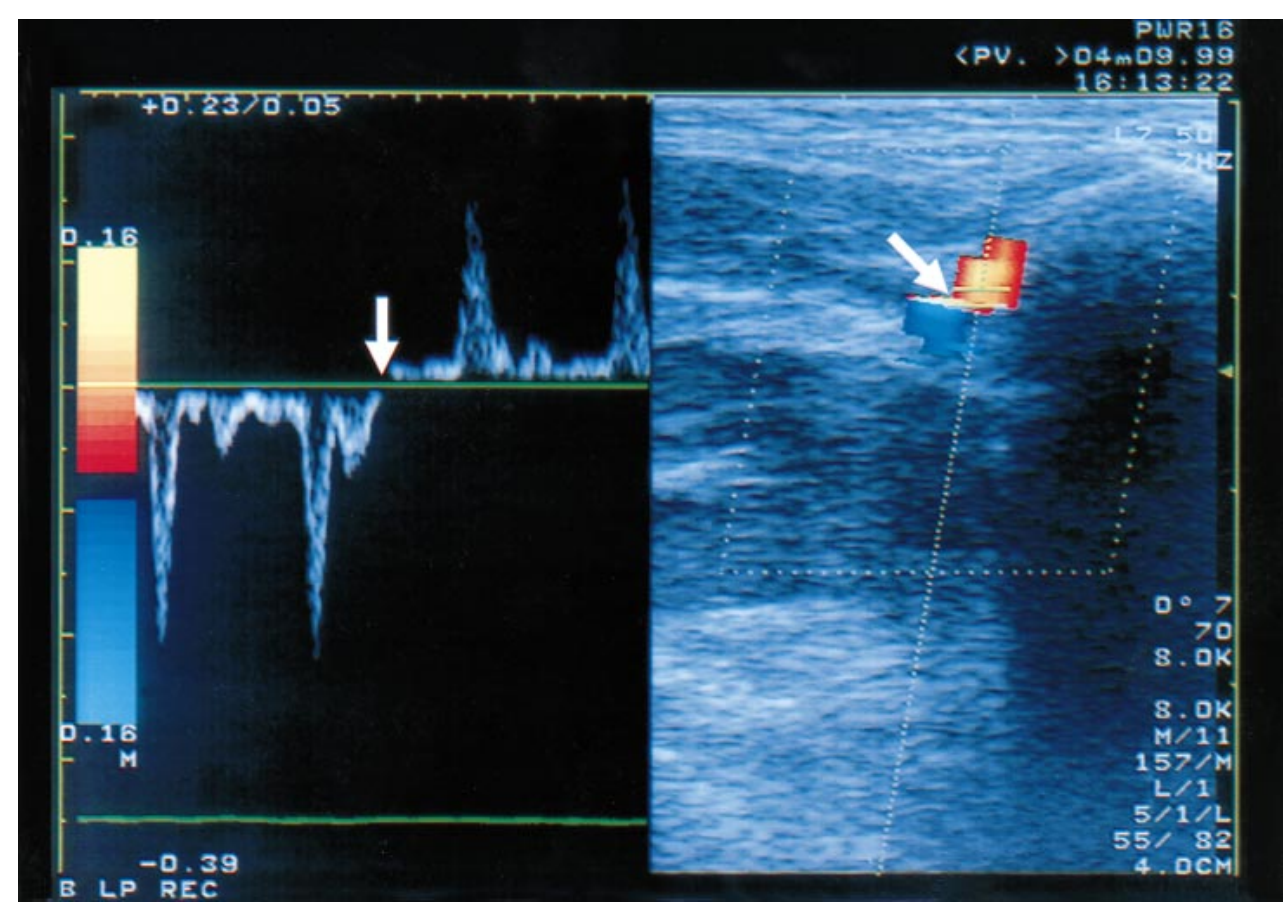

Fig 1. The direction of the RA flow in the anatomic snuff-box was backward with RA compression. The blue signals became red signals after RA compression (arrow).

Table I. Hand circulation in Allen's test

\begin{tabular}{lccc}
\hline & Before RA compression & After RA compression & P value \\
\hline Maximum flow velocity of RA in the snuff-box $(\mathrm{cm} / \mathrm{s})$ & $33.9 \pm 18.5(18$ to 50$)$ & $-18.5 \pm-9.1(-7$ to -42$)$ & .0001 \\
Digital artery systolic pressure $(\mathrm{mm} \mathrm{Hg})$ & $118.6 \pm 12.8(88$ to 144$)$ & $104.4 \pm 15.2(75$ to 126$)$ & .0019 \\
\hline
\end{tabular}

Data presented are mean value \pm standard deviation and the range of measurements. $R A$, Radial artery.

from the probe changed to the signals toward the probe with RA compression (Fig 1). Maximum flow velocity of the RA in the snuff-box and digital pressure significantly decreased with RA compression $(P=.0001$ and $P=.0019$, respectively $)$ (Table I).

Discussion. In the traditional Allen test, accuracy depends on the ability to feel the ulnar arterial pulsation with RA compression. ${ }^{2,3}$ In the modified Allen test for which the Doppler probe is used without color Doppler function, the accuracy depends on the ability to hear the Doppler sounds of the palmar artery with RA compression. ${ }^{3}$ These subjective preoperative evaluations may not be sufficient to minimize the false results of the Allen test. A more objective method is essential to avoid digital ischemia after RA harvesting.

Starnes and associates ${ }^{3}$ reported that measuring the pressure of the digits may be an alternative method to Allen's test. Our results also demonstrated a significant decrease of digital systolic pressure with RA compression. This method has the advantages of being noninvasive, simple, and objec- tive. However, digital pressure criteria that can accurately predict digital ischemia after RA harvesting have not yet been clarified. ${ }^{3,4}$

The RA in the anatomic snuff-box runs between the first metacarpal bone and the second carpal bone from the dorsal side to the palmar side..$^{5}$ The insonation angle anatomically near $0^{\circ}$ from the RA in the snuff-box to the probe provides an optimal color Doppler study. Measurement and evaluation of the Doppler flow velocity of the RA in the snuff-box with RA compression demonstrate hand circulation after RA harvesting, because this position is the most distal ulnar artery territory and because the flow direction was backward in all hands in our study. Therefore we propose that the vanishing of its flow after RA compression is an indicator of digital ischemia after RA harvesting. The snuff-box technique has the advantages of being objective and more accurate than Doppler study without color Doppler techniques. Criteria using the reduction of flow velocity with RA compression must be established in future studies. 


\section{REFERENCES}

1. Nunoo-Mensah J. An unexpected complication after harvesting of the radial artery for coronary artery bypass grafting. Ann Thorac Surg 1998;66:929-31.

2. Kamienski RW, Barnes RW. Critique of the Allen test for continuity of the palmar arch assessed by Doppler ultrasound. Surg Gynecol Obstet 1976;142:861-4.

3. Starnes SL, Wolk SW, Lampman RM, Shanley CJ, Prager RL,
Kong BK, et al. Noninvasive evaluation of hand circulation before radial artery harvest for coronary artery bypass grafting. $\mathrm{J}$ Thorac Cardiovasc Surg 1999;117:261-6.

4. Husum B, Berthelsen P. Allen's test and systolic arterial pressure in the thumb. Br J Anaesth 1981;53:635-7.

5. Agur AMR. The upper limb. In: Gardner JN, editor. Grant's atlas of anatomy. 9th ed. Baltimore: Williams \& Wilkins; 1991. p. 353450 . 